\section{Biology's variable logic}

SIR - Is is not time to reconsider seriously the concept that applied mathematics (physics style) is not relevant to the training of bioscientists? Or should we continue to obey Kantor's law of the conservation of ignorance, namely that an incorrect concept accepted, taught and used for many years by many intelligent people is hard to change: and the less the concept is understood, the harder it is to change?

Thirty years ago, the management of the chemical company I worked for, as an applied mathematician, assigned me to the Animal Science Group, which was experimentally comparing three types of synthetic substitutes for dietary methionine for improving the growth of chickens from day-old to market age. The group was not particularly happy about this, as they already had a statistician well versed in Fisher's approach to biological experimentation, and it was already known that mathematics was not relevant to biology. I saw Brody's Bioenergetics and Growth on their desks, but they said they didn't use it.

My assignment was to get some idea why there was so much confusion between the experimental results of our research group and the various academic groups that were engaged to test the products under conditions and with chickens as closely like ours as possible. I found that the basal diets used were somewhat different because the local ingredients varied, as was expected; the methods of incorporating the additives in the basal differed; the durations of the experiments varied so that there were differences in the mean weight gains for chicks; and the statistical treatment of the data differed.

However, my study, beginning with the historical background of the experimental techniques used in such nutritional studies, seemed to make it clear that a major cause of the confusion was the lack of a commonly known and not too difficult to understand theory of how animals grow, depending on the composition of the freely fed diets.

My colleagues were aware of my work; a few understood but most did not and rejected it anyway in favour of what the majority were thinking and doing. I later published a book ${ }^{1}$ on the approach I was taking.

Recently, L. M. Potter et $a l^{2}$ have presented a study of the same kind of confusion and controversy surrounding the same problem I had to deal with in the 1960 s. The state of affairs then and now is typified by the following quotation from their paper.

\footnotetext{
Although a variety of studies exist on the methionine active compounds available to the feed industry, results show apparent variations because experimental designs and basal diets differ among studies and therefore it is risky and possibly inaccurate to draw conclusions from the literature without careful observation Periods within a study can even alter results.
}

Obviously, selection of particular studies can influence the position one establishes.

Is it not a great shame that so many young people have been trained over the past 50 years to accept such work as scientific and worthy of publication, and that the peerreview process can only fail due to the insidious character of Kantor's law? Can we be sure the same situation is not also present in other fast-growing fields of biology?

JOHN R. PARKS

Department of Animal Husbandry,

University of Sydney,

Sydney, NSW 2006, Australia

1. Parks, J. R. A Theory of Feeding and Growth of Animals, (Springer, Berlin, 1982).

Potter, L. M., Schmidt, G. P., Blair, M. E., Shelton, J. R. \& Bliss, B. A. Animal Nutrition and Health, March-Apri (1984).

\section{Missing the point}

SIR - The term 'computational biology' is very new to science, even newer than the term 'computational chemistry'. As a field distinct from both theoretical biology and mathematical biology, computational biology can be simply defined as the application of computational methods to the study of biological systems. As such, the scope of computational biology is as broad as the range of computational methods at our disposal and the extent of biological problems intriguing us. Examples of applications of computational biology include modelling and simulation of dynamic processes at each hierarchic level from biomolecules up to societies of organisms, as well as modelling the structure and organization of each of these levels and how that relates to function. Computational biology problems arise in biochemistry and molecular biology, physiology, ecology, evolutionary biology and so on.

I am concerned that some members of the scientific community may have too narrow a view of this field and that others may adopt this narrow view, to the detriment of the field. For example, two recent symposia in the United States ${ }^{1,2}$ which were presented as symposia on 'computational biology' actually focused on a subset of computational biology, that of research in protein and nucleic acid sequence comparison and biomolecular structure. The use of the term 'computational biology' in the scientific literature has also reflected the same limited scope $^{3}$. Baylor College of Medicine and Rice University have established a Center for Computational Biology, but at least twothirds of the faculty are specialists in biomolecular structure.

This narrow use of 'computational biology' is unfortunate, because the scope of this field is actually much wider. In the same sense that applications of computational chemistry are not restricted to quantum mechanics and molecular dynamics but also include chemical kinetics and prediction of organic reactions, applications of computational biology include everything from protein structure to predator-prey population dynamics to systems physiology.

While the narrow use of 'computational biology' may reflect greater attention to biomolecular structure as a result of the Human Genome Project, this use may result in insufficient appreciation for other areas of biology that are being studied by computational means. Recognition of the success of and future potential for computational biology in dealing with questions of human health and world ecology will begin by understanding its widespread applicability.

MARK E. LACY Norwich Eaton Pharmaceuticals, Inc. PO Box 191, Bldg 42, Norwich, New York 13815, USA

1. Albany Conference on 'Converging Approaches in Computational Biology', Rennselaerville, NY, 13-16 September 1990

2. The W. M. Keck Symposium on Computational Biology, Houston, Texas, 17 November 1990

3. Kingsbury, D. T. Trends Biotech. 7, 82-87 (1989).

\section{Frosty foods}

SIR - The notes on some innovations and inventions, "refrigeration (1895)", "frozen foods (first sales 1930)" and "food preservatives (1873)" in Jesse H. Ausubel's article (Nature 350, 649; 1991) require modification.

Refrigeration became available on an industrial scale from the development, by $\mathrm{D}$. Boyle, of the compression-expansion refrigerator using ammonia as the heat transfer fluid in 1872 .

Frozen food (meat) was first imported into the United Kingdom (from Australia) in 1880 and by 1910 imports had risen to more than 500,000 tons a year.

A novel food preservative may have been developed in 1873 but the general principle exemplified by the use of salt, sulphur and sulphur dioxide had been used since preRoman times.

W. F. J. CUTHBERTSON

4 Coopermill Lock, Canalside, Harefield, Middlesex UB9 6JA, UK

\section{Source please}

SIR - Although the authors of "Bayesian reasoning in science" (Nature 350, 371; 1991) mentioned Bayes's original work, entitled "An essay towards solving a problem in the doctrine of chances", they did not reference it. His original work, although rather lengthy, is available quite easily in The Philosophical Transactions of the Royal Society of London, 53, 370-418 (1763). A correct reference should always be given to source material.

R. J. L. HOOPER

Department of Clinical Biochemistry, Royal Brompton \& National Heart

Hospital,

Sydney Street, London SW3 6NP, UK

NATURE · VOL $351 \cdot 6$ JUNE 1991 